\title{
NOTES A UNA TRADUCCIÓ DELS EVANGELIS
}

\author{
Joan F. Mira
}

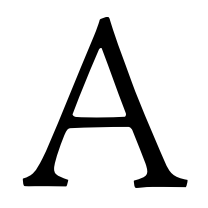

portar un paper modest a l'homenatge a un savi immens té, en el meu cas, un component personal. He viscut gran part dels meus anys a la ciutat de Castelló, on la família de la meua esposa mantenia, i manté, una relació llarga i cordial amb els Colón: el pare era el fotògraf familiar, i una de les germanes, mestra, era companya i amiga de la meua sogra. Afortunadament (no sempre passa...), la seua ciutat sempre ha considerat Germà Colón com un dels seus fills més insignes, i no li han faltat les mostres públiques de reconeixement. He tingut la fortuna de participar en algun d'aquests actes, especialment a la Universitat Jaume I.

$* * *$

Els llibres que es consideren revelats, doctrinals, els fonaments d'una religió, solem mirar-los com si estigueren al marge de la literatura, i per tant fora dels interessos d'un autor o un traductor literari. Dit d'una altra manera: ‘a qui li interessen aquests textos antics i remots si no és als fidels de la religió que fonamenten? I què importa, llavors, la qualitat o la forma diguem-ne literària d'una traducció, a condició que siga ortodoxa i canònica? I d'una altra manera encara: ¡té algun sentit, alguna gràcia, llegir l'Alcorà o els evangelis no com a font de doctrina sinó pel pur plaer de la lectura, com llegiria Homer, Dante o Flaubert? En el cas de l'Alcorà, després d'haver-ne fet l'experiència en la traducció exacta i exemplar de Míkel de Epalza, no n'estic del tot segur. En el cas dels evangelis, sí.

La qüestió no és banal: ¿̇encara té algun sentit, a hores d'ara, traduir textos sagrats com els del Nou Testament, tan repetidament editats, i que alhora se suposa que desperten un interés tan escàs fora dels cercles d'especialistes o potser dels creients i devots? La resposta era sempre la mateixa: sí, i té sentit perquè formen un llibre magnífic que el públic ignora, perquè les traduccions que hi ha no em fan el pes com a lector de literatura, i perquè estic convençut que la importància cultural de l'obra que coneixem com a Nou Testament mereix una versió nova i diferent. I aquesta és justament la qüestió, la diferència: es tractava, en efecte, de 
l'intent de fer una versió «literària», i no doctrinal ni dogmàtica, dels evangelis i d'altres textos neotestamentaris. És a dir d'una versió feta amb els mateixos criteris que hauria aplicat a la traducció de qualsevol text narratiu, teatral o poètic de la literatura clàssica, i més concretament de la literatura en llengua grega.

Les traduccions conegudes i més o menys canòniques del Nou Testament segueixen els criteris que sempre han seguit les versions dels «textos sagrats»: transmetre la doctrina, ajustar-se a la tradició i al magisteri de l'església. Es tracta, indefectiblement, de versions que d'una banda són, per dir-ho d'alguna manera, reverencials, i de l'altra estrictament funcionals, ja que des del moment que el text original és vist com a inspirat, sagrat, i portador d'un missatge teològic i ètic, la seua traducció ha tingut sempre com a base la interpretació de la paraula suposadament inspirada per l'Altíssim, i com a objectiu central o únic la transmissió d'aquest missatge, doctrinal i moral, que la divinitat envia als humans. Fins $i$ tot l'exegesi moderna, els estudis bíblics i l'anàlisi lingüística són en realitat instruments, moderadament cientifics, per arribar a aquest mateix objectiu: la concreció històrica i l'autenticitat de la doctrina, el rigor i l'exactitud com a fonament o justificació del dogma. No cal dir que, sota aquesta perspectiva, la qualitat literària o narrativa del text, i fins $i$ tot el sentit general i «comú» (no doctrinal o dogmàtic) del vocabulari i dels recursos expressius, passen a segon terme o simplement no són presos en consideració. Com a resultat d'aquests criteris, explícits o implícits, el text —vist i traduït com a text sagrat, no com a producte literari- difícilment arribarà al lector sense la càrrega afegida dels sentits que s'hi han acumulat amb el pas dels segles.

És a dir, els evangelis ens arriben carregats amb el pes de la teologia moral o dogmàtica, amb la tradició de l'imaginari cristià, i també amb el valor reductiu de moltes paraules i expressions en bona part condicionades per la traducció llatina de sant Jeroni coneguda com la Vulgata. Per posar un exemple simple i conegut: la frase Magnificat anima mea Dominum, les cèlebres paraules de Maria en versió llatina, habitualment apareix traduïda com «La meua ànima magnifica el Senyor»; però ¿és això una expressió diguem-ne normal per una joveneta de poble, en el llenguatge narratiu actual, no en el canònic i tradicional? I en tot cas, ¿què 
significa, i com és possible que algú magnifique el Senyor, és a dir que faça o considere Déu més gran encara de com és? El verb grec megalúnein, significa, en tot cas, reconéixer o expressar la grandesa d'algú, que és la idea atribuïda a Maria; de manera que, si traduïm: «La meua ànima diu "el Senyor és gran"», la frase ja té un aspecte més real i fins i tot més intel.ligible per al lector contemporani. I en l'escena de l'anunciació, si les paraules de l'àngel (és a dir del missatger) són «Déu te guard, plena de gràcia, el Senyor és amb tu», formulen una salutació ben canònica, on la paraula «gràcia» està inevitablement carregada d'un sentit teològic afegit: la gràcia és un concepte complicat, que la teologia ha anat elaborant amb el pas dels segles, i que certament en la frase de salutació del missatger celestial no podia contenir tanta càrrega doctrinal com després ha rebut la paraula. Jo puc traduir «Alegra't: el Senyor t'atorga el seu favor i t'acompanya», que no és una traducció literal, ni tampoc una fórmula de salutació habitual (de fet el narrador diu que «ella, en sentir-ho, es va torbar, i cavil.lava quina mena de salutació era aquella»), però que no inclou un concepte, la noció de gràcia, que només molt més tard passà a formar part de la difícil metafísica del dogma. A continuació, com és ben conegut, quan Maria rep la notícia que s'ha de quedar embarassada, pregunta «I com es farà això, si jo no conec home?» (versió de Montserrat), amb una expressió ben tradicional però gairebé impossible en un llenguatge narratiu actual: qui podria escriure, ara, allò de «conéixer home»? O pregunta «Com podrà ser això, si jo soc verge?» (traducció interconfessional), cosa que no diu de cap manera el text grec. Vull dir que «conéixer home» és una expressió ben estranya per a un lector modern, i que la virginitat no és el tema de la resposta de Maria, sinó un tema afegit bastant més tard, quan la narració dels orígens de Jesús es carregà de referents més o menys mítics. La noia vol dir, simplement, que no viu amb un home, que no fa vida conjugal, i per tant no entén com pot quedar-se prenyada. I si Maria, al final de la visita, li diu al missatger del cel «Heus aquí l'esclava del Senyor; que es faci en mi segons la teva paraula», cal reconéixer que una expressió com aquesta, tan canònica i tan difosa, resulta una forma de parlar ben allunyada d'un llenguatge que el lector d'ara puga veure com a normal; o siga, qui podia o pot parlar així? Jo he traduït: «Soc l'esclava del Senyor», digué Maria, «que faça amb mi això 
que m'has dit». La idea, evidentment, és la mateixa, però no sona igual. La primera versió, la tradicional i acreditada, sembla bastant improbable en boca d'una noia de poble; la segona, la meua, crec que resulta perfectament imaginable.

Per començar, doncs, abans de traduir hi ha una qüestió de lectura; és a dir, com a què llegim aquells papers, com a quina mena d'obra: sagrada o profana, divina o humana, teològica o literària, narrativa o doctrinal. Dit d'una altra manera, i posant-nos en la perspectiva del públic a qui anaven originalment dirigits aquells textos: la primera condició, o la primera afirmació, és que ha de ser possible llegir ara mateix els evangelis i els altres llibres del Nou Testament, traduits a un llenguatge narratiu contemporani, d'una manera semblant a com els podia llegir un lector mínimament culte - però un lector no cristià- d'Alexandria, de Pèrgam, de Siracusa o de Nàpols a principis del segle II $\mathrm{dC}$. Ja sé que això no és possible del tot, evidentment, i que la lectura no serà la mateixa, però cal fer-hi un petit esforç. Perquè quan, en les versions tradicionals i canòniques, nosaltres llegim «paràbola», aquell lector devia llegir «exemple» o «comparació», quan llegim «Esperit Sant» ell llegiria «alé sagrat» (deixeu-me, ací, fer un parèntesi important: aquell lector del segle II o del segle III ni tan sols podia imaginar que aquest alé, buf o esperit, aquest pneuma, fóra una persona divina i autònoma, diferent del Pare i del Fill, ja que aquesta lectura o interpretació únicament té sentit en el context d'un dogma, la Trinitat, que encara no existia com a tal: l'Esperit Sant és un producte de l'especulació teològica dels segles següents); i allà on en les nostres traduccions habituals llegim «miracle» aquell lector en llengua grega entenia «prodigi» o «fet extraordinari», quan llegim «ressuscitar» ell llegia «despertar»o «aixecar-se», quan llegim «pecat» ell llegia «culpa», «falta»o «error». I així podríem continuar amb multitud de paraules i expressions que tenen, en primer lloc, un sentit literal, general o comú, històric o cultural, abans de tenir un sentit consagrat i canònic ajustat a la tradició cristiana i a l'evolució de la teologia dogmàtica.

I d'altra banda, a l'hora de pensar en la naturalitat d'una lectura contemporània, hi ha el to sovint solemne i una mica encarcarat que solen tenir les traduccions més clàssiques i acreditades, un exemple de les quals seria la versió dels monjos de Montserrat, del 1960, versió magnífi- 
ca d'altra banda des de tots els punts de vista. Però quaranta o cinquanta anys després la narració, molt sovint, queda condicionada per un llenguatge literari que no ha suportat massa bé el pas del temps. Com això: «Aleshores digué Pere: Senyor, ¿és a nosaltres que dieu aquesta paràbola, o també a tots? El Senyor respongué: ¿Qui és doncs l'administrador fidel, prudent, que l'amo posarà al cap del seu servei per distribuir al seu temps la ració de menjar? Sortós aquell servent que l'amo, quan arribi, trobi fent-ho així; en veritat us dic que el posarà sobre tots els seus béns». Fagment que jo he traduït així: «Senyor,» li va dir Pere, «aquest exemple es refereix a nosaltres, o a tothom?» «Qui és doncs,» continuà el Senyor, «l'administrador lleial i prudent, a qui l'amo encomanà la gent de casa i la distribució puntual de les racions de blat? Feliç aquell esclau si quan arriba el senyor troba que ho està fent així: no dubteu que el posarà al front de totes les seues possessions». El to no és el mateix. Hi ha, també, alguna altra forma de traduir que intenta un llenguatge més popular, però sempre rigorosament cristià, amb resultats de vegades ben incoherents quant a l'estil i el to, com és el cas, per exemple, de la versió catalana de l'Editorial Claret: dir «Hola, rei dels jueus», francament no m'arriba a convéncer. I en qualsevol dels casos, com que l'objectiu és posar a l'abast del lector el sentit doctrinal, amb expressions que en faciliten la comprensió, el resultat pot ser una versió apta sobretot per a la catequesi, com la del Nou Testament de la Bíblia catalana, traducció interconfessional, on massa vegades és ben dubtosa la correspondència amb el valor expressiu del text original.

Mirat amb la perspectiva habitual, tot això, en realitat, té una lògica: si els llibres del Nou Testament són textos sagrats, sobrenaturalment inspirats o revelats, i si la seua traducció ha de servir sobretot els creients que hi busquen el missatge i la doctrina, és obvi que qualsevol altra consideració és secundària, o fins i tot pertorbadora d'aquesta funció central. En l'extrem d'aquesta perspectiva hi hauria la consideració del text purament com a paraula divina, fins i tot en la seua pura literalitat i en la llengua mateixa de l'Altíssim. Com es fa amb l'Alcorà, que segons la visió rigorosa de l'islam no podria ni tan sols ser traduit, ja que Al.là el va dictar en àrab al Profeta i aquesta «versió original» és l'única autèntica $\mathrm{i}$ l'única possible. Sense arribar tan lluny, també les versions consagrades 
de la Bíblia han sigut molt de temps tan intocables com la traducció de sant Jeroni, la Vulgata llatina, com ara la King James Bible que al llarg de quatre segles ha estat, i està, present en totes les cases de soca anglosaxona, o com la Bíblia de Luter, que a més de fundar una nova manera de llegir es va convertir també, a través de la lectura, en un dels fonaments de l'alemany literari. En qualsevol cas, i qualsevol que siga la tradició, la lectura dels textos sagrats, en les societats que en tenen de clàssics i canònics, ha estat sempre una pràctica lligada directament a la fe, no a la literatura. Una conseqüència de tot això és que aquests llibres i escrits són percebuts pel públic i per la societat exactament com els presenten les mesquites, les sinagogues o, en el cas del cristianisme, les esglésies. És a dir com un conjunt de textos d'interés exclusivament religiós, com a matèria de lectures piadoses, com a tema de reflexió i d'estudi, com a element i aliment de la litúrgia o de la vida espiritual dels fidels.

I la conclusió és ben simple: en el cas del Nou Testament i en un temps, com el nostre, de laïcisme general, ningú no llegeix els evangelis, o els viatges $\mathrm{i}$ les cartes de $\mathrm{Pau}$, o un text tan fascinant com el llibre de l'Apocalipsi. Vull dir que l'antiga lectura piadosa d'aquells textos és ja ben minoritària, i alhora ningú no els llegeix com a simple lectura d'una obra important, interessant, literària o històrica. I això és una desgràcia lamentable, és el tall radical d'una història cultural de vint segles: perquè, en especial i en primer lloc el conjunt dels quatre textos que porten els noms de Marc, Mateu, Lluc i Joan, formen simplement el llibre més important de la història d'Europa. Els evangelis, en efecte, formen un llibre, o un conjunt de narracions que van entreteixint la realitat històrica del protagonista, la crònica dels seus fets i paraules, la pura creació i la fantasia més o menys lligada amb recursos d'ordre mític: el resultat és una obra que des del moment mateix de la seua redacció, fins els nostres dies, ha tingut un pes, una difusió, una influència i una penetració cultural i social com cap altre llibre imaginable de cap llengua o literatura europea. Més que cap clàssic grec o llatí, en aquest sentit, més que cap obra medieval o moderna, més que Dante, Cervantes, Shakespeare o Dostoievski. I no m'estendré per demostrar obvietats: Jesús de Natzaret i sa mare Maria, son pare Josep el fuster, els companys Pere, Jaume o Joan, Llàtzer i Maria Magdalena, $i$ tants altres noms, són personatges que formen part -o han 
format part, fins ara- de l'imaginari popular europeu amb més potència i difusió que Hamlet, el Quixot o els germans Karamàzov. I les imatges de l'anunciació a Maria, del naixement de Jesús a Betlem, la multiplicació dels pans i dels peixos, Pilat rentant-se les mans, la crucifixió o la resurrecció (o les imatges impressionants de les visions al-lucinades de l'Apocalipsi), són escenes i temes narratius no superats en difusió a través dels segles. Sense comptar la seua omnipresència en les arts plàstiques: és prou visitar qualsevol museu, o fullejar una història de l'art. Temes i imatges no superats en difusió popular fins el nostre temps, és clar, quan el coneixement d'aquestes escenes $\mathrm{i}$ dels seus protagonistes comença a quedar reduït a cercles de creients cada vegada més estrets, o es queda en simple curiositat per a visitants de museus i d'esglésies: una curiositat, per cert, que cada any que passa va quedant més condicionada i més limitada per la ignorància creixent de la matèria narrativa que és fonament de les imatges. ¿Quin sentit té, quin contingut, la contemplació de l'esplèndida Glòria de Bernini, a Sant Pere del Vaticà, per qui no sap que aquell colom d'on surten els raigs daurats és un colom diví, l'alé de Déu, sant? $\mathrm{O}$ què pot veure en la deliciosa Anunciació de Fra Angelico qui no sap que representa l'instant fundacional de tota la tradició cristiana?

Però hi ha, a més a més, el valor propi literari dels textos, que són textos únics i originals: la forma evangeli és una creació gairebé sense precedents - i sense continuació com a subgènere literari, si en parlem amb una mica de rigor-, com no té precedents ni equivalents, si més no en la tradició mediterrània $\mathrm{i}$ europea, un personatge com el seu protagonista. Totes les religions aparegudes en societats més o menys urbanes i amb escriptura, tenen textos sagrats: paraules del fundador, paraula directament divina, narracions mítiques d'herois o de déus, revelacions o especulacions, o una combinació d'elements diversos. Però cap no ha produit, en els seus orígens $\mathrm{i}$ com a text fundacional, unes narracions tan directes $\mathrm{i}$ tan simples, tan clarament populars en la seua redacció (populars, ací, vol dir que no són obra de sacerdots o de lletrats, ni obra del fundador mateix, sinó basades en la transmissió oral), i amb un llenguatge tan diàfan i d'una eficàcia tan immediata i tan clara. Com en aquestes escenes de l'evangeli de Lluc que per mi, llegides en aquell grec tan planer, són una 
pura delícia, i que he mirat de traduir conservant el to de narració meravellosa que té l'original:

El sisé mes, Déu va enviar el missatger Gabriel a una vila de Galilea que es diu Natzaret, a visitar una noia que estava compromesa en matrimoni amb un home que es deia Josep, de la casa de David, i el nom de la noia era Maria. L'àngel entrà i li digué:

«Alegra't: el senyor t'atorga el seu favor i t'acompanya!» Però ella, en sentir-ho, es va torbar, i cavil.lava quina mena de salutació era aquella.

«No tingues temor, Maria,» li va dir el missatger: «Déu t'ha concedit el seu favor, $i$ ara et quedaràs embarassada i pariràs un fill. Li posaràs de nom Jesús: $i$ serà gran, l'anomenaran fill de l'altíssim, i el senyor Déu li donarà el tron de David, el seu pare. Regnarà sobre la casa de Jacob, segles i segles, i el seu regnat no tindrà fi.»

«Com pot ser això, si no visc amb cap home?», li va dir Maria al missatger. I l'àngel li va contestar:

«Vindrà damunt de tu un alé sagrat i et cobrirà l'ombra del poder de l'altíssim. Per això, allò que ha de nàixer és sant i l'anomenaran fill de Déu. I mira, Elisabet, la teua parenta, també ha concebut un fill en la seua vellesa, i ja està de sis mesos, ella que la tenien per estèril: per a Déu no hi ha paraula impossible.»

«Soc l'esclava del senyor», digué Maria: «que faça amb mi això que m’has dit.» I el missatger va desaparéixer.

Pocs dies més tard, Maria es va posar en camí, a bon pas, cap a un poble de la muntanya de Judea; i en arribar entrà a la casa de Zacaries i saludà Elisabet. I va passar una cosa: que quan Elisabet escoltà la salutació de Maria la criatura va saltar d'alegria en el seu ventre, i un alé sant va omplir Elisabet, que va exclamar amb veu molt forta:

«Beneïda tu, més que cap dona, i beneït el fruit de les teues entranyes! I com és això, que la mare del meu senyor ve a visitar-me? Saps que quan la veu de la teua salutació m'ha arribat a les orelles ha saltat d'alegria l'infant que porte en les entranyes? Feliç la que confia que es compliran les paraules que li arriben de part del senyor». I Maria va dir:

«La meua ànima diu "el senyor és gran”, i el meu esperit està exultant, amb Déu salvador meu, perquè ell mirà la humilitat de la seua esclava i així, des d'ara, totes les generacions em diran afortunada: perquè ell, el poderós, ha fet amb mi coses 
extraordinàries. El seu nom és sant, i és bo i generós amb els qui el temen, de generació en generació. Mostra la força del seu braç i dispersa els arrogants de pensament i de cor. Fa caure dels seus setials els poderosos i exalta els humils, omple de béns els afamats $i$ als rics els despatxa amb les mans buides. No oblida la seua bondat $\mathrm{i}$, tal com els ho va dir als nostres pares, protegeix Israel, servidor seu, i Abraham i la seua descendència, per sempre.» Maria es va quedar amb ella uns tres mesos, i després sén tornà a casa.

Algú es podria preguntar si això és un «clàssic», i si és realment un clàssic grec. Doncs, la resposta és que sí: no són clàssics només aquells textos que tenen autor conegut, Sòfocles o Plató, Dante o Cervantes, sinó aquells que han assolit la condició de norma o paradigma d'una forma de narrar, d'escriure, de parlar o de fer poemes. Vull dir que també és clàssica una part de la producció dita popular, dels poemes èpics, de les rondalles i contes, de tantes $i$ tantes mostres sense les quals la literatura quedaria ben trista i empobrida. I clàssiques són, sobretot, aquelles obres que han donat matèria, argument, imatges i escenes a tota una tradició literària: sense la matèria evangèlica, per exemple, caldria reescriure gran part de la literatura europea, i els resultats són impossibles d'imaginar. Els llibres del Nou Testament pertanyen, d'altra banda, a l'extensa producció escrita en llengua grega, la que comença amb Homer i no sabem on acaba. Estan escrits en aquell grec comú, llengua koiné, que durant alguns segles parlà tanta gent del Mediterrani oriental i d'Itàlia mateixa: el grec de les ciutats de Síria, d'Antioquia, d'Alexandria i de Pèrgam, el grec que sabien els mercaders i la gent de mar, que era com un grec internacional, no exactament el d'Ėsquil o Tucídides, però un grec que, quan el trobem escrit, és notablement correcte: el mateix que entenia i llegia un romà mitjanament culte. Allò que devien trobar estrany, per tant, els primers lectors gentils o pagans, no era la llengua, sinó la forma narrativa, tan diàfana i directa, i sobretot el contingut meravellós. Com en aquest passatge de l'evangeli de Joan:

Poc després, Jesús tornà a pujar a Jerusalem, amb motiu d'una festa dels jueus. A Jerusalem, al costat de la porta de les Ovelles, hi ha una gran bassa per als banys, que en hebreu es diu Betzata, i que té cinc porxades, on solia jaure una multitud de malalts, cecs, coixos o invàlids. Allà, doncs, hi havia un home que ja portava trenta-vuit anys de malaltia, i Jesús, quan el va veure gitat, i sabent quant de temps feia que hi era, li va dir: «Vols posar-te bo?» «Senyor,» respongué el ma- 
lalt, «no tinc ningú que em fique dins de la bassa quan es remou l'aigua: quan jo hi arribe, algú hi ha entrat abans.» (Perquè de tant en tant baixava un àngel $i$ removia l'aigua de la bassa, i el primer que hi entrava després de remoure's l'aigua quedava curat del mal que tingués). «Alça't,» li diu Jesús, «agafa la teua llitera i camina.» Immediatament, l'home es va posar bo, va agafar la llitera i començà a caminar. Aquell dia era dissabte, i alguns dels caps dels jueus li van dir a l'home que s'havia curat: «Avui és el sàbat: no pots anar carregat amb la llitera, no està permés.» «El qui em va curar em digué: agafa la llitera i camina.» «I qui és l'home que t'ha dit això?», li preguntaren; però ell, el guarit, no sabia qui era, ja que Jesús havia desaparegut entre la gentada que hi havia per allà.»

Llegir aquestes narracions extraordinàries des de fora (des de fora del dogma i de l'església) pot ser encara més interessant i atractiva que si es fa des de dins: llegir els evangelis - $\mathrm{i}$ els fets dels apòstols amb els viatges $i$ aventures de Pau, o les fantasies terribles de l'Apocalipsi- com a obra literària, pot resultar més satisfactori que llegir-los com a text sagrat. Llegir-ho en grec té l'avantatge d'entrar-hi en contacte a través d'un llenguatge original, immediat, sense rigideses ni solemnitats afegides per les versions dogmàtiques habituals. Poder llegir-ho, traduit, com a literatura, demana, òbviament, fer-ne una traducció literària. I aquesta lectura és la que la meua versió ha volgut fer possible. El meu propòsit, doncs, traduint textos sagrats com si no fossen sagrats (o amb el to i el sentit que tenien abans de ser sagrats) era fer llegir aquesta obra extraordinària als qui altrament no la llegirien mai, i fer-la llegir d'una altra manera als qui potser l'han llegida a trossos. Si se'm permet l'al.lusió, es tractava d'un projecte equivalent al que vaig dur a terme, abans, traduint la Divina Comèdia, i després traduint l'Odissea: fer llegir una gran obra oblidada.

Una traducció d'aquestes característiques només era possible partint, en primer lloc, d'una llarga familiaritat amb la llengua grega, i també d'uns fonaments sòlids en la cultura religiosa cristiana: prou sòlids per poder-la tenir sempre present $i$, alhora, deixar-la contínuament al marge. És una faena llarga i complexa, plena de paranys que cal evitar constantment, i de resultat sempre incert, però sempre estimulant. Una faena que cal acompanyar constantment amb la consulta d'estudis, glosses, notes, versions múltiples al català i a d'altres llengües (castellà, francés, italià, anglés, llatí), per tal d'assegurar-se del sentit original de 


\section{Revista de Filologia}

cada fragment, de cada frase i sovint de cada mot: sempre posant-se en la pell de qui escrivia i llegia, fa prop de vint segles, en aquell grec que era llengua comuna de cultura i de comunicació, sempre amb por de no interpretar amb prou rigor el valor de les paraules $i$ les frases, sempre dubtant del resultat, sempre mirant d'ajustar un to i un llenguatge contemporani nostre però no radicalment allunyat de l'antic. Sempre sabent que era una empresa delicada, que molt possiblement suscitaria crítiques tècniques - sense dubte raonades - per part dels especialistes, $\mathrm{i}$ escàs entusiasme per part del gremi de la literatura. Tant se val: no treballava pensant en els filòlegs, teòlegs o escripturistes, ni pensant en els crítics literaris. Treballava pensant en els possibles lectors i en el plaer o l'interés que hi pogueren trobar en la lectura.

Castelló, tardor del 2004 - estiu del 2020 